\section{BMJ Open Respiratory Research}

\title{
Driving performance in patients with chronic obstructive lung disease, interstitial lung disease and healthy controls: a crossover intervention study
}

\author{
Thomas Skovhus Prior, ${ }^{1}$ Thomas Troelsen, $^{2}$ Ole Hilberg ${ }^{1}$
}

To cite: Skovhus Prior T, Troelsen T, Hilberg 0. Driving performance in patients with chronic obstructive lung disease, interstitial lung disease and healthy controls: a crossover intervention study. BMJ Open Resp Res 2015;2:e000092.

doi:10.1136/bmjresp-2015000092

Received 19 May 2015 Revised 29 July 2015 Accepted 30 July 2015

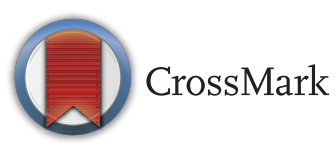

${ }^{1}$ Department of Respiratory Medicine and Allergology, Aarhus University Hospital, Aarhus C, Denmark ${ }^{2}$ Department of Anesthesiology, Regional Hospital of Randers, Randers, Denmark

Correspondence to Dr Thomas Skovhus Prior; thomas_prior@hotmail.com

\section{ABSTRACT}

Introduction: Cognitive deficits in patients suffering from chronic obstructive pulmonary disease (COPD) have been described and hypoxaemia has been addressed as a possible cause. Cognitive functions in patients with interstitial lung disease (ILD) are not well studied. These patients are taking part in everyday traffic, but little is known regarding their driving performance. This study was conducted to determine the driving performance in patients with COPD and ILD, respectively compared to healthy controls using a driving simulator. Additionally, the effect of oxygen supply was addressed.

Methods: 16 patients with COPD (8 receivers and 8 non-receivers of long-term oxygen therapy (LTOT)), 8 patients with ILD (consisting of idiopathic interstitial pneumonias) and 8 healthy controls were tested in a driving simulator. Each test lasted $45 \mathrm{~min}$. In the oxygen intervention part of the study the patients were randomised to receive oxygen therapy in the first or second test and acted as their own controls.

Results: Patients with COPD had significantly impaired driving performance when comparing SD from the centre of the road and number of off-road events to controls. Patients with COPD receiving LTOT performed significantly worse than those not receiving LTOT when comparing SD and worse than the patients with ILD when comparing SD and off-road events. Patients with ILD performed similarly to controls (SD: LTOT 2.39*; no LTOT 0.69*; ILD 0.37; controls 0.36 ; ${ }^{*} \mathrm{p}<0.05$. Off-road: LTOT 226.67*; no LTOT 78.92*; ILD 40.00; controls 25.78; $\left.{ }^{*} p<0.05\right)$. Oxygen therapy had no effect on driving performance.

Conclusions: Patients with ILD performed similarly to controls in the driving simulator, whereas patients with COPD showed decreased driving performance, especially those receiving LTOT. Doctors should be aware of this when renewing the driving license of patients with COPD. Oxygen therapy showed no effect on driving performance.

Trial registration number: NCT02125916

\section{INTRODUCTION}

Cognitive deficits caused by chronic obstructive pulmonary disease (COPD) are well

\section{KEY MESSAGES}

First study to investigate the driving performance in patients with interstitial lung disease.

- Patients with chronic obstructive pulmonary disease with and without long-term oxygen therapy were included.

- Driving simulator with automated registration of several measures of motor functions and cognitive abilities.

- Crossover design to limit confounding on oxygen intervention.

described, and hypoxaemia is known to cause cognitive impairment. Up to $77 \%$ of patients with hypoxaemic COPD have cognitive deficits, and especially perceptual-motor integration is affected. Simple motor tasks such as speed, strength and coordination are also affected. ${ }^{1-3}$ Patients with nonhypoxaemic COPD also have decreased cognitive functions. ${ }^{45}$ The cognitive functions of patients with interstitial lung disease (ILD) are not well described. So far only a single study of patients with sarcoidosis showing cognitive dysfunction has been reported. ${ }^{6}$

Driving a car is a complex process requiring integration of a series of cognitive functions, including perception, attention, motor integration, reaction time and coordination. These are exactly the cognitive functions affected by hypoxaemia. Only two former studies have focused on driving capabilities in patients with COPD; to our knowledge, no studies have been made in patients with ILD. Patients with COPD performed significantly worse during a driving simulation compared to healthy controls, ${ }^{7}$ and acute oxygen supply showed no effect on short-term driving performance in these patients. ${ }^{8}$ The number and life expectancy of patients with COPD will increase in the future. ${ }^{9}$ This may send more and maybe more disabled 
patients on the roads. The Danish Health and Medicines Authority demands that patients receiving long-term oxygen therapy (LTOT) use a portable oxygen supply when driving, despite poor evidence to support this.

The current study was conducted to determine driving performance during a longer period of time in patients with COPD and ILD, respectively compared to healthy controls using a driving simulator. Additionally, the study investigated the effect of oxygen supply on driving capability.

\section{MIATERIAL AND IMETHODS}

Patients were recruited from a university hospital department (Aarhus, Denmark). In order to be included the patients had to be 18-65 years and have a diagnosis of either COPD or ILD. The patients were included continuously until the required numbers had been obtained in each group according to the power calculation (see 'Statistics'). The patients were divided into three groups:

1. Eight patients with COPD, forced expiratory volume in $1 \mathrm{sec}\left(\mathrm{FEV}_{1}\right)<50 \%$ of expected value, receiving LTOT.

2. Eight patients with $\mathrm{COPD}, \mathrm{FEV}_{1}<50 \%$ of expected value, not receiving LTOT.

3. Eight patients with ILD (consisting of idiopathic interstitial pneumonias), diffusion capacity of the lung for carbon monoxide (DLCO) $<50 \%$ of expected value, not receiving LTOT.

Patients with COPD had to be in a stable phase of their disease to participate. Patients with other conditions affecting their cognitive function or preventing them from operating the driving simulator were excluded.

Arterial oxygen tension $\left(\mathrm{PaO}_{2}\right)$ had to be $<7.3 \mathrm{kPa}$ in a stable phase of the patient's disease to receive LTOT while receiving optimal medical treatment. $\mathrm{PaO}_{2}$ $<8.0 \mathrm{kPa}$ was required to receive LTOT, if the patient had cor pulmonale, chronic heart failure or haematocrit level $>0.55$. No patients suffered from severe hypercapnia (all patients had an arterial carbon dioxide tension $\left.\left(\mathrm{PaCO}_{2}\right)<7,0 \mathrm{kPa}\right)$.

Eight healthy controls without pulmonary disease were recruited from the same geographical area and were matched to the patients on age and gender. An equal number of men and women were recruited in all groups. All participants were current drivers.

The study was approved by the Danish Data Protection Agency and the Central Denmark Region Committee of Biomedical and Research Ethics. The participants gave written and informed consent before participating in the study. Participants were informed that all results were confidential and had no legal impact or influence on retaining their driving license.

\section{Driving simulator}

A driving simulator was used to compare driving performance of patients with COPD or ILD versus controls and to measure the effect of oxygen supply in patients with COPD and ILD, respectively. The driving simulator was computer-based and developed by Land and Horwood. ${ }^{10}$ The screen showed a road ending in the horizon in a night setting. A steering wheel was used to keep the car in the centre of the winding road. At the same time the participants had to look to the edges of the screen where a random series of numbers (0-9) changed. Each time the number ' 2 ' occurred, they had to press a button on the steering wheel in order to measure divided attention and reaction time. The same simulation setting was used in all tests. The participants had a 5 min test drive to get familiar with the simulator. Each test lasted $45 \mathrm{~min}$.

In the oxygen intervention part of the study, a crossover study design was used; thus the patients with COPD or ILD were tested both with and without oxygen supply and acted as their own controls in this part of the study. The patients were randomised to receive oxygen supply in the first or second test. Before the test there was a 30 min wash-in or wash-out period before or after the oxygen supply. The patients receiving LTOT received their normal flow of oxygen; other patients received $2 \mathrm{~L} / \mathrm{min}$. Oxygen saturation was measured to ensure a saturation of at least $92 \%$ during the test. The controls were only tested once without oxygen supply.

Outcome parameters of the tests were SD from the centre of the road, number of off-road events per hour, number of failing to press the button at the occurrence of number ' 2 ' and average response time to the occurrence of number ' 2 ' in seconds.

\section{Statistics}

Differences in outcome parameters between patient groups and controls and differences in outcome parameters within patient groups with and without oxygen supply were calculated as medians with IQRs and tested, using the Mann-Whitney's U-test, as data were not normally distributed. Furthermore, all patient groups were compared with each other without oxygen supply on all outcome parameters, using one-way analysis of variance on ranks (Kruskal-Wallis) and Tukey's test, to identify significantly different means. Results were reported as median values and IQRs. Two-tailed $p$ values $<0.05$ were considered statistically significant. Based on power calculations, we included eight patients in each group (presumed mean group difference of 2.0 in SD, of 0.81 $\alpha=0.05 \beta=0.1$ ). Power calculations were based on preliminary data using the same methods as described above. The analyses were conducted using statistical software package Sigmaplot V.11.0 (Systat Software, Inc, San Jose, USA).

\section{RESULTS}

Twenty-four patients with chronic lung diseases were enrolled in the study. We included eight patients with COPD receiving LTOT, eight patients with COPD not 
Table 1 Data of the participants

\begin{tabular}{|c|c|c|c|c|c|}
\hline & Age (median), years & Male/female & $\begin{array}{l}\text { FEV } \\
\text { (\% of expected value) }\end{array}$ & $\begin{array}{l}\text { FVC } \\
\text { (\% of expected value) }\end{array}$ & $\begin{array}{l}\text { DLCO, \% of } \\
\text { expected value }\end{array}$ \\
\hline COPD, LTOT & $58-64(63.5)$ & $4 / 4$ & $0,52-1,69$ I (17-49) & 1,33-2,22 I (34-55) & - \\
\hline COPD, no LTOT & $51-64(60.0)$ & $4 / 4$ & $0,38-1,30$ । (14-47) & $0,80-2,81$ । (24-57) & - \\
\hline ILD & 39-60 (51.0) & $4 / 4$ & $1,24-2,41$ I (47-84) & $1,69-4,34$ I (54-97) & $38-47$ \\
\hline Controls & $44-61(55.0)$ & $4 / 4$ & - & - & - \\
\hline
\end{tabular}

COPD, chronic obstructive pulmonary disease; DLCO, diffusion capacity of the lung for carbon monoxide; $\mathrm{FEV}_{1}$, forced expiratory volume in $1 \mathrm{sec}$; FVC, forced vital capacity; ILD, interstitial lung disease; LTOT, long-term oxygen therapy.

receiving LTOT and eight patients with ILD not receiving LTOT. In the control group eight healthy subjects were enrolled. Gender distribution was similar in all four groups (table 1). One patient with ILD was excluded from the study, as he was not able to operate the driving simulator. He was replaced by another patient with ILD complying with the inclusion criteria.

The group of patients with COPD receiving LTOT had significantly impaired driving skills when comparing SD and off-road events to controls. Furthermore, these patients performed worse than the patients with COPD not receiving LTOT as measured by SD and worse than the patients with ILD as measured by SD and off-road events. The patients with COPD not receiving LTOT also had significantly impaired driving skills when comparing SD and off-road events to controls. The reaction times and non-response rates of the two groups of patients with COPD were not significantly different compared to the controls. There was no significant difference in driving performance between patients with ILD and controls in any of the outcome parameters. No differences were found when comparing reaction times and non-response between any of the patient groups (table 2, figure 1). There was no significant difference in any of the analysed outcome parameters when comparing patients within the same group with versus without oxygen supply (table 3 ).

\section{DISCUSSION}

The current study demonstrated a decreased driving performance by the patients with COPD; patients with ILD performed similarly to controls on all parameters.
Both groups of patients with COPD regardless of whether they received LTOT or not performed worse than controls in terms of SD and off-road events; patients with COPD receiving LTOT also performed worse than those not receiving LTOT when comparing SD and worse than the patients with ILD when comparing SD and off-road events.

These results corresponds to some of the results from a study performed by Orth et $a l^{7}$ They compared 17 patients with non-hypoxaemic COPD and 10 healthy controls in a driving simulator for $60 \mathrm{~min}$, measuring concentration faults and accident frequency. There were no differences in concentration deficits, but patients with COPD had a higher accident frequency than controls. There was no correlation between lung function, disease severity, sleep architecture or nocturnal ventilation and driving performance. In concordance with the present study, Orth et al found decreased driving performance in patients with COPD but on different parameters. The driving simulator used by Orth et al registered only accidents, for example, crashes with other cars and some concentration faults, but SD, off-road events and other concentration faults were registered manually by a technician observing the subject. Thus, results were based on a more subjective measures compared to the present study. The patients with COPD tested by Orth et al caused more accidents, whereas there were no differences in non-responses and reaction time between COPD and controls in the present study. This may be explained by the decreased capabilities of steering the simulator among the patients with COPD; they might react fast enough, but their decreased

Table 2 Results reported as median values (IQRs)

\begin{tabular}{|c|c|c|c|c|}
\hline \multirow[b]{2}{*}{ Outcome parameters } & \multicolumn{2}{|l|}{ COPD } & \multirow[b]{2}{*}{$\begin{array}{l}\text { ILD } \\
\text { No oxygen }\end{array}$} & \multirow[b]{2}{*}{$\begin{array}{l}\text { Controls } \\
\text { No oxygen }\end{array}$} \\
\hline & $\begin{array}{l}\text { LTOT } \\
\text { No oxygen }\end{array}$ & $\begin{array}{l}\text { No LTOT } \\
\text { No oxygen }\end{array}$ & & \\
\hline $\begin{array}{l}\text { SD from the centre of the } \\
\text { road }\end{array}$ & $2.39(1.93-2.89) \#^{*}$ & 0.69 (0.49-0.87) \# & $0.37(0.31-0.41)$ & $0.36(0.30-0.43)$ \\
\hline Off-road events (no) & 226.67 (129.72-481.29) \#† & 78.92 (33.72-102.92) \# & $40.00(18.00-47.34)$ & $25.78(2.67-64.67)$ \\
\hline Non-response (seconds) & $3.0(0.0-13.0)$ & $1.5(1.0-2.5)$ & $1.0(0.0-2.0)$ & $2.0(0.0-5.0)$ \\
\hline Response time (seconds) & $3.19(2.72-5.28)$ & $2.55(2.47-2.95)$ & $3.09(2.59-4.61)$ & $3.73(2.49-4.59)$ \\
\hline
\end{tabular}


Standard Deviation
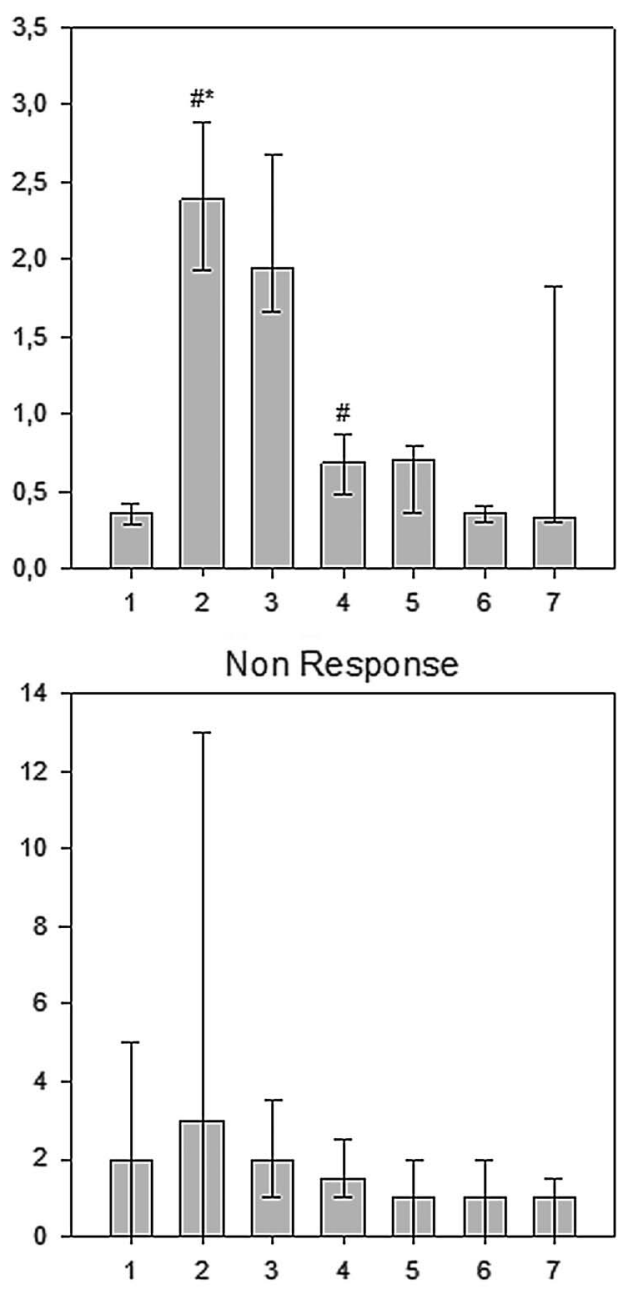

Off Road Events

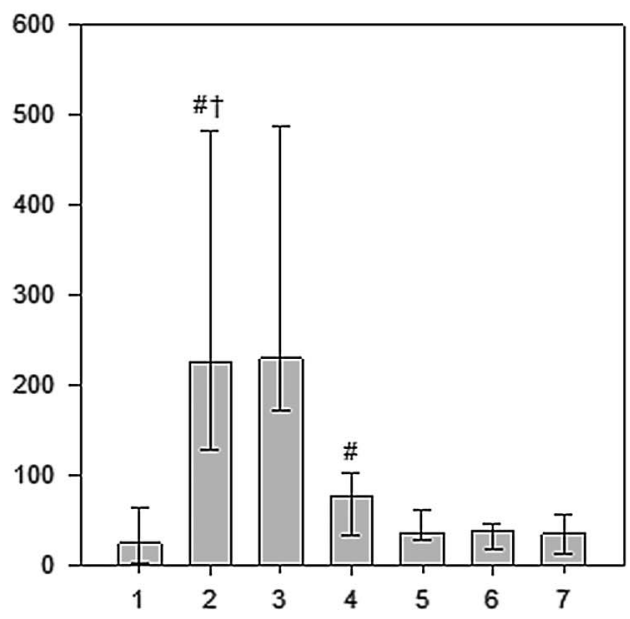

Reaction Time

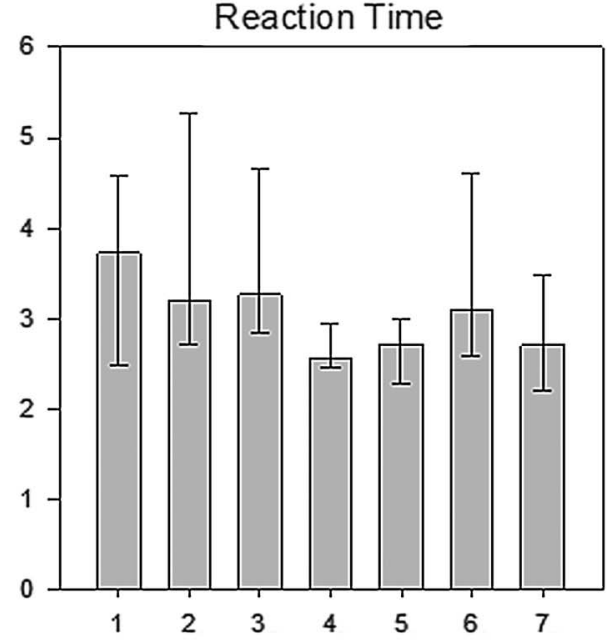

Figure 1 1. Controls; 2. LTOT COPD without oxygen; 3. LTOT COPD with oxygen; 4 . No LTOT COPD without oxygen; 5 . No LTOT COPD with oxygen; 6. ILD without oxygen; 7.ILD with oxygen. Bars depict mean values, error bars IQR. COPD, chronic obstructive pulmonary disease; ILD, interstitial lung disease; LTOT, long-term oxygen supply.

perception-motor integration made them unable to steer the car around the obstacles in front of them. Orth et al found no correlation between disease severity and driving performance whereas the present study found decreased performance among the patients with COPD receiving LTOT compared to those not receiving LTOT on some parameters. LTOT is not mentioned by Orth et $a l$ and it is unknown whether any of the patients included in their study received LTOT.

This study did not show any effect of oxygen supply on improvement in performance in the driving simulator. These results corroborate findings by Pretto JJ and McDonald CF, ${ }^{8}$ who found no effect of acute oxygen supply on cognitive and driving performance in 30 patients with hypoxaemic COPD. They performed a 20 min driving simulation and a 10 min psychomotor vigilance task on a group of patients with COPD of whom 21 of 30 received LTOT. The patients were tested while receiving intranasal air or oxygen, and they found no effect of the acute oxygen supply compared to air.
They did not distinguish between patients with or without LTOT and the driving simulation event was considerably shorter than the 45 min simulation of the current study. Even though patients in the current study were divided into separate groups, and patients with COPD receiving LTOT were deprived of their regular oxygen supply during one of the test drives, and even though the length of the driving simulation events were longer, we did not demonstrate any effect of the oxygen supply.

Another study on the effect of oxygen supply compared to breathing room air did not shown any effect. Wilson $e a^{11}$ tested 10 patients with hypoxaemic COPD receiving LTOT breathing either oxygen (to achieve $\mathrm{Sa}_{2}>90 \%$ ) or room air and examined speed of information processing, ability to detect correct sequence of tones, serial memory, critical flicker fusion and story recall. Receiving acute oxygen supply did not significantly affect the outcomes.

The effect of oxygen supply to healthy subjects to reduce fatigue and increase reaction time has been 


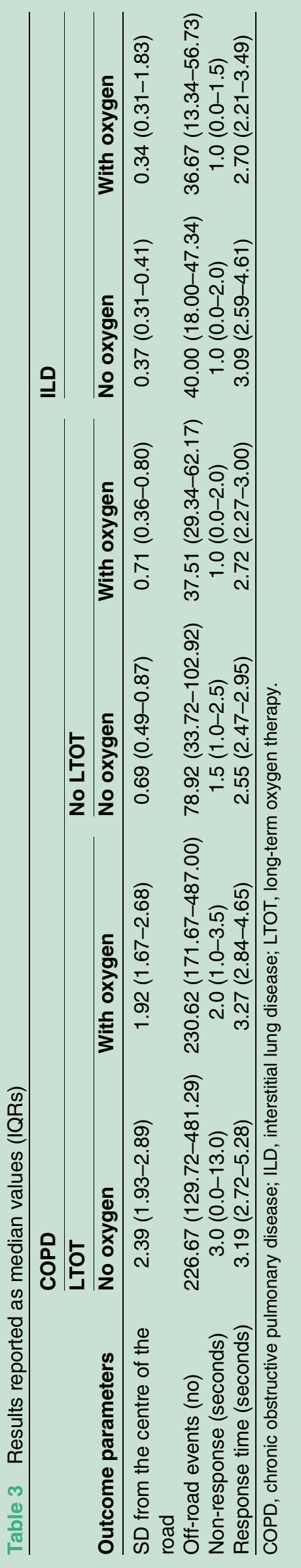

examined by Sung et al ${ }^{12}$. 10 male subjects received increasing amounts of oxygen (18-30\%) in a driving simulator. Their subjective feeling of fatigue was measured as well as their reaction time, when they were asked to break suddenly after $2 \mathrm{~h}$ of driving. Both outcomes were decreased with higher amounts of oxygen. The study design was based on a subjective feeling of fatigue and the driving simulator was not used to assess driving performance during the test. Thus, results are difficult to apply to real life situations.

A study conducted by Karakontaki et $a l^{13}$ showed that patients with even mildly hypoxaemic COPD had decreased cognitive skills. They compared 35 patients with COPD and mild hypoxaemia $\left(\mathrm{PaO}_{2}>55 \mathrm{~mm} \mathrm{Hg}\right)$ to 10 healthy controls in an attention/alertness battery of tests used to evaluate driving performance. The patients performed significantly worse than controls, and both $\mathrm{FEV}_{1}$ and $\mathrm{PaO}_{2}$ were correlated to the decreased cognitive skills.

This leads to speculations whether hypoxaemia is the cause of impaired cognitive function in patients with COPD. Grant et $a l^{1}$ found a significant, but weak correlation between $\mathrm{PaO}_{2}$ and cognitive performance ( $\mathrm{r}$ approximately 0.2) in a study of 203 patients with hypoxaemic COPD. Fix et $a l^{2}$ showed a small, but significant reduction in cognitive skills in 66 patients with COPD, and that impairment was correlated to $\mathrm{PaO}_{2}$. Hypoxaemia can as such explain some, but not all cognitive deficits in patients with COPD. Other causes of $\operatorname{cog}$ nitive impairment have been proposed. Comorbidities such as vascular disease are present in up to $50 \%$ of patients with $\mathrm{COPD},{ }^{14}$ and vascular risk factors are known to cause decreased cognitive performance. ${ }^{15}$ Cognitive impairment in patients with COPD is different from patients with multi-infarct dementia. ${ }^{16}$ Increased $\mathrm{PaCO}_{2}$ may cause cognitive impairment. Some studies have shown a correlation between $\mathrm{PaCO}_{2}$ and cognitive function, ${ }^{16-18}$ whereas others were unable to find such a correlation. $^{2}{ }^{19}$ The causes of cognitive deficits in COPD patients are multiple.

The patients with ILD in the current study performed similarly to the controls on all parameters. The patients with COPD receiving LTOT had significantly decreased driving performance compared to patients with ILD when comparing SD and off-road events. ILD does apparently not affect cogntive performance in the same manner as COPD. This also indicates that hypoxaemia is not the only cause of cognitive deficits in patients with COPD. Differences between the two groups of patients in terms of comorbidities, social status and other factors affecting cognitive functions may influence their driving performance, but these are not addressed in the current study.

Elfferich et $a t^{6}$ found cognitive impairment in 343 patients with sarcoidosis compared to healthy controls using a self-reported questionnaire. The questionnaire included attention, perception, memory and motor functioning in everyday life; some of the same cognitive 
functions are used for driving. The results are different from the current study, but this may be explained by the differences in a subjective measure of cognitive impairments in everyday life compared to the objective measures of using a driving simulator. Another difference is that the current study included patients with sarcoidosis as well as other ILDs. The cognitive performance of patients with ILD is still an area of research and more evidence is warranted.

The strengths of the study are the crossover design in the oxygen intervention part of the study to limit confounding as patients acted as their own controls. Information bias was limited by using a driving simulator with automatic registration of driving performance. Confounding due to sex differences was reduced by the equal number of men and women in all groups. Selection of participants from the hospital department could introduce selection bias, but inclusion of both patients with COPD with and without LTOT represented different severities of the disease. A limitation of this study was the difference in age among the groups. As cognitive impairment may increase with age, this may in part confound our results. Both the patients with ILD and the controls were younger than the patients with COPD, and this may in part explain why they performed better than the patients with COPD. The level of education of the patients and controls was not evaluated, and this may also have confounded the results. Level of education may affect cognitive performance, but we assume that using a driving simulator is not significantly affected by differences in level of education. This study has included a small number of patients with COPD and ILD, respectively, and as such the patients included may not be completely representative of all patients with these diseases. Larger studies should be conducted in order to support our findings.

We conclude that patients with ILD perform similarly to controls in the driving simulator, whereas patients with COPD showed decreased driving performance, especially those receiving LTOT. Doctors should be aware of this when renewing the driving license of patients with COPD. The supply of oxygen showed no effect on driving performance. As hypoxaemia may be a cause of cognitive impairment, we still recommend that patients receiving LTOT receive oxygen supply while driving.

Funding This research received no specific grant from any funding agency in the public, commercial or not-for-profit sectors.

Competing interests None declared.

Ethics approval the Central Denmark Region Committee of Biomedical and Research Ethics.
Provenance and peer review Not commissioned; externally peer reviewed.

Data sharing statement No additional data are available.

Open Access This is an Open Access article distributed in accordance with the Creative Commons Attribution Non Commercial (CC BY-NC 4.0) license, which permits others to distribute, remix, adapt, build upon this work noncommercially, and license their derivative works on different terms, provided the original work is properly cited and the use is non-commercial. See: http:// creativecommons.org/licenses/by-nc/4.0/

\section{REFERENCES}

1. Grant I, Heaton RK, McSweeny AJ, et al. Neuropsychologic findings in hypoxemic chronic obstructive pulmonary disease. Arch Intern Med 1982;142:1470-6.

2. Fix AJ, Golden CJ, Daughton D, et al. Neuropsychological deficits among patients with chronic obstructive pulmonary disease. Int $J$ Neurosci 1982;16:99-105.

3. Prigatano GP, Parsons O, Wright E, et al. Neuropsychological test performance in mildly hypoxemic patients with chronic obstructive pulmonary disease. J Consult Clin Psychol 1983;51:108-16.

4. Favalli A, Miozzo A, Cossi S, et al. Differences in neuropsychological profile between healthy and COPD older persons. Int J Geriatr Psychiatry 2008;23:220-1.

5. Liesker JJ, Postma DS, Beukema RJ, et al. Cognitive performance in patients with COPD. Respir Med 2004;98:351-6.

6. Elfferich MD, Nelemans PJ, Ponds RW, et al. Everyday cognitive failure in sarcoidosis: the prevalence and the effect of anti-TNF-alpha treatment. Respiration 2010;80:212-19.

7. Orth M, Diekmann C, Suchan B, et al. Driving performance in patients with chronic obstructive pulmonary disease. J Physiol Pharmacol 2008;59(Suppl 6):539-47.

8. Pretto JJ, McDonald CF. Acute oxygen therapy does not improve cognitive and driving performance in hypoxaemic COPD. Respirology 2008;13:1039-44.

9. Mathers CD, Loncar D. Projections of global mortality and burden of disease from 2002 to 2030. PLoS Med 2006;3:e442.

10. Land M, Horwood J. Which parts of the road guide steering? Nature 1995;377:339-40.

11. Wilson DK, Kaplan RM, Timms RM, et al. Acute effects of oxygen treatment upon information processing in hypoxemic COPD patients. Chest 1985;88:239-43.

12. Sung EJ, Min BC, Kim SC, et al. Effects of oxygen concentrations on driver fatigue during simulated driving. Appl Ergon 2005;36:25-31.

13. Karakontaki F, Gennimata SA, Palamidas AF, et al. Driving-related neuropsychological performance in stable COPD patients. Pulm Med 2013;2013:297371.

14. Report of The National Chronic Obstructive Pulmonary Disease Audit 2008: clinical audit of COPD exacerbations admitted to acute NHS units across the UK, Royal College of Physicians of London, British Thoracic Society and British Lung Foundation. 2008:1-81. https://www.rcplondon.ac.uk/sites/default/files/report-of-the-nationalcopd-audit-2008-clinical-audit-of-copd-exacerbations-admitted-toacute-nhs-units-across-the-uk.pdf (accessed 12 May 2015).

15. Aleman A, Muller M, de Haan EH, et al. Vascular risk factors and cognitive function in a sample of independently living men. Neurobiol Aging 2005;26:485-90.

16. Incalzi RA, Gemma A, Marra C, et al. Chronic obstructive pulmonary disease. An original model of cognitive decline. Am Rev Respir Dis 1993;148:418-24.

17. Incalzi RA, Gemma A, Marra C, et al. Verbal memory impairment in COPD: its mechanisms and clinical relevance. Chest 1997;112:1506-13.

18. Parekh PI, Blumenthal JA, Babyak MA, et al. Gas exchange and exercise capacity affect neurocognitive performance in patients with lung disease. Psychosom Med 2005;67:425-32.

19. Grant I, Prigatano GP, Heaton RK, et al. Progressive neuropsychologic impairment and hypoxemia. Relationship in chronic obstructive pulmonary disease. Arch Gen Psychiatry 1987;44:999-1006. 